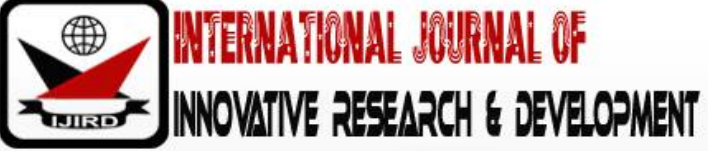

ISSN 2278 - 0211 (Online)

\section{Water Hyacinth in Lake Victoria: Tackling the Root Causes}

\author{
Dr. John 0. Kakonge
}

President, Association of the Former International Civil Servants of the United Nations

\begin{abstract}
:
Lake Victoria is an asset of inestimable value to the countries of the region, to the continent of Africa, and, given its immense size and ecosystem properties, to the entire planet, to the global climate and to our very survival. It is therefore a matter of extreme urgency that the Lake be saved from the scourge of the water hyacinth, which threatens it with devastation. This article pinpoints the main causes of the spread of this pestilential weed, which must be tackled urgently. Adequate funding, deployment of qualified agricultural extension workers, a radical change in farmers' attitudes, political support, genuine commitment by national and county governments and a lake basin approach, with rigorous application of the polluter pays principle - these are all measures critical to success of the endeavour to rid the Lake of the hyacinth. Strong leadership is needed at the highest levels and the work should start now - immediately - before the portion of the Lake in Kenya is completely choked by a massive carpet of hyacinth: some of it live, sucking nutrients out of the water and some of it dead, rotting and toxic. Left unattended, impoverished communities which derive their livelihoods from the Lake will sink deeper and inexorably into poverty.
\end{abstract}

Keywords: Water hyacinth, Lake Victoria, integrated lake basin management, polluter pay principle, political will and support

\section{Introduction}

\subsection{Kenya's Most Precious Water Asset}

By surface area, Lake Victoria is the world's second largest freshwater lake, containing 2,500 cubic kilometres of water - the ninth largest repository of freshwater in the world. No surprise, therefore, that it is one of Kenya's most important water resources - perhaps the most important. It accounts for about $96 \%$ of the country's total fish production (Deloitte, 2015), and is a major source of food, energy, water for domestic and industrial use, shelter and transportation (Lake Victoria Environment Report, 2018).Over 10 million people, representing one fourth of Kenya's population, derive their livelihoods from within the Lake Basin region (Deloitte, 2015). Accordingly, Lake Victoria has the potential to be an excellent blue economy resource. After hosting the first international Sustainable Blue Economy Conference in 2018, and in line with Sustainable Development Goal 14, Kenya has committed itself to conserving and sustainably using its water resources, including, above all, those of Lake Victoria.

\subsection{Pressures on the Lake: Status Quo and Way Forward}

Despite the immense economic and social potential of Lake Victoria, itis increasingly under pressure from a variety of interlinked human activities and has become a vast dumping ground for industrial, domestic and agricultural wastes. Pollution, sedimentation, eutrophication, overfishing and invasion by water hyacinth are all negatively affecting the ecology of the lake, and this in turn has serious consequences for communities living in the basin frontier counties of Migori, Homa Bay, Kisumu, Siaya and Busia.

The focus of this brief is the socio-economic and political factors that have contributed to the contamination of Lake Victoria's waters, and which consequently have facilitated the spread of water hyacinth. Following that is a discussion of the mitigating measures which could potentially reduce the decline of water quality and control the growth and spread of the weed.

\subsection{Origin of the Invasive Weed}

Originating in the Amazon Basin of Brazil, water hyacinth has invaded many African waterways and covers thousands of hectares of Lake Victoria's surface. A study by Makhanu (1997), indicated that the aquatic weed thrives and spreads in environments characterized by shallow water; quiescent water; bed surfaces covered with organic matter and rich in sediments; and water areas where key mineral nutrients such as phosphorus and nitrogen are available. Owing to its potential to rapidly reproduce and spread, the weed has inhibited activities such as fishing and transportation in the lake. In addition, the dense mats that it forms create a microhabitat for vectors of disease, thereby affecting human health. The resulting reduction in fish catch and increase in diseases is having a severely detrimental impact on the livelihoods of individuals dependent on the lake. 


\section{Influence of Human Activities on the Spread of Water Hyacinth}

Donors, international organizations and even the Kenyan government have conducted studies and carried out programmes to combat water hyacinth through a variety of methods. Mechanical, biological and chemical approaches have been undertaken to remove the weed. However, despite these efforts, the weed continues to flourish primarily because of nutrient producing human activities adjacent to the lake that include poor agricultural practices, urbanization, unchecked pollution from industries and widespread poverty. Additionally, inadequate human capacity and funding and the lack of an integrated Lake Basin management approach, are all hampering the eradication of water hyacinth and sustainable use of the lake's water.

\subsection{Poor Agricultural Practices}

Land use practices within Lake Victoria's catchment area have caused substantial sedimentation, pollution and overall deterioration of water quality. Practices such as draining of wetlands, clearing of forest cover for additional arable land, and cultivation on river banks and adjacent slopes, have resulted in high levels of sedimentation. Furthermore, overstocking of livestock has been increasing, resulting in overgrazing and subsequent soil erosion. This degradation and conversion of wetlands through cultivation has rendered them incapable of buffering pollution and sediments from the catchment. Consequently, agricultural, municipal and industrial wastes freely enter the lake.

Intensive use of agrochemicals in the form of fertilizers and pesticides applied to boost farm yields, has caused a high flow of nutrients into the lake. An analysis by Muyodi et al. (2011), demonstrated that the excessive amount of nutrients that wash into Lake Victoria has resulted in eutrophication, a condition characterized by algal blooms, excessive growth of aquatic weeds such as water hyacinth, and oxygen-depletion in the bottom waters, contributing to fish kills and loss of habitat. According to UNESCO (2016), the River Nyando and its associated basin exhibit these highly polluted and deteriorated characteristics.

\subsection{Urbanization}

Urbanization has been identified as one of the interlinked human activities related to in-migration and population growth that has put the lake under pressure (UNESCO, 2016). Towns have continued to mushroom along the lakeshore and adjacent catchment areas as people move there in search of livelihoods, especially from the fishing industry. To sustain these urban centres, land has been cleared for agricultural use and industrial development, while wetlands that are supposed to act as pollution buffers, have been converted into settlement areas.

The Lake Victoria Environmental Management Programme (LVEMP), funded by the World Bank, noted that many urban centres within the lake basin are contributors of pollution that enters the water system through spillage, ineffective municipal sewer systems and surface runoff. Discharge of untreated sewage was identified in the LVEMP as the main source of water pollution originating from urbanization. Towns in the Lake Victoria Basin have continued to experience burgeoning population growth. However, physical infrastructure, such as sewer lines, have not been improved to meet the demand. For example, a UNESCO (2016) study in Homa Bayfound that the sewage treatment works constructed in 1982 had a design capacity of $750 \mathrm{~m}^{3}$ per day, but the current daily raw wastewater flow was in excess of 2,000 $\mathrm{m}^{3}$ per day. Consequently, the treatment works were producing a final effluent that was of a very poor quality and that was being discharged directly into the lake. The problem is further exacerbated by the fact that in the town of Homa Bay, only $22 \%$ of the population is connected to the sewerage network. The situation in Kisumu is nobetter, with the Kisumu Water and Sewerage Company causing high levels of pollution by discharging treated effluent directly into the Kibos and Kisat rivers. Additionally, contaminated urban surface runoff carrying oils and other municipal waste contaminate the lake's water.

\subsection{Industrial Pollution}

There has been a growing public outcry, especially in Kisumu, because of industries in the area pumping raw effluent directly into streams and thereby threatening the lives of thousands of people dependent on that water for domestic use. For instance, in February 2019, the National Environment Management Authority (NEMA), reviewed claims that Kibos Sugar Millers, Muhoroni Agrochemical and two prisons were polluting local rivers. A UNESCO (2016) study on emerging pollutants noted that industries such as breweries, tanning, fish processing, agro-processing and abattoirs were key pollution sources in the Lake Victoria catchment. The study further established that major rivers draining into the lake traverse through industrial and agricultural zone and thus transport industrial pollutants into the lake. For instance, River Nzoia carries effluent from We buye paper mills, textile factories in Eldoret and sugar industries mainly located at Mumias and Kakamega. River Nyando transports effluents from Muhoroni Sugar Company and the Agro-Chemical and Food Company Limited, while River Kuja receives effluents from coffee and tea processing factories in the Kisii highlands. As noted by Nyabundi (2019), sugar industries have been put on the spot, with Kibos Sugar having been found to be releasing toxic chemicals into the River Kibos, thus creating a fertile ground for the proliferation of aquatic invaders like water hyacinth and hippo grass.

The Lake Victoria Environment Report of 1996 observed that there was an incremental increase of metal concentrations in the lake's waters. The source most likely resulted from industries in urban centres within the lake basin discharging wastes into receiving rivers. Industrial pollution has been exacerbated by non-implementation and monitoring of pollution regulations by the relevant authorities. 


\subsection{Poverty}

As noted by the LVEMP, the challenges facing the lake are not only environmental but also have everything to do with people's livelihoods in terms of food security, employment and their hope for a better future (World Bank, 2018). People will do anything for survival, even if it means contributing to environmental degradation.

According to the World Bank (2018), the Lake Victoria Basin area is concentrated with poor populations who are dependent on natural resources. More than half of the people within these communities live on less than \$1.25 per day. The basin has a population density of 300 persons per $\mathrm{km}^{2}$ which is substantially higher than the African average of 36 . Basin poverty rates for Kenya stand at $43.4 \%$. Through their reliance on natural resources, these communities exert considerable pressure on the lake and adjacent land and forests.

Incidences of poverty among the Lake Basin communities, characterized by poor sanitation conditions, over-dependence on wood fuel and unsustainable farming practices, have led to pollution and sedimentation of the lake. Poverty pushes populations to dwell in slum areas with limited sanitation facilities. The end result of such settlements is the channelling of most of their wastes into rivers that drain into the lake. Notably, some industries and factories that pay little attention to environmental conservation, have employed people from these poor local communities, while continuing to pollute the environment.

In order to meet food demands for the growing Lake Basin population, local communities have sought to increase the extent of arable land and settlement areas. This has led to unsustainable land use practices such as the clearance of forests, filling-in of wetlands, cultivation along river banks and over-grazing of arable land. These activities have further deteriorated the quality of the lake's water due to soil erosion and the resulting sedimentation and through the washing of agro-chemicals into rivers. To add to the problem of ecosystem destruction, the majority of the Lake Basin populations rely on wood fuels for energy resulting in the clearance of forests for firewood.

\subsection{Inadequate Capacity}

Though regulations and authorities tasked with ensuring water and environmental quality exist, pollution and environmental degradation persist. For example, UNESCO (2016), observed that weak monitoring and ineffective enforcement of regulations were a concern. The situation has been attributed to incapacity in terms of manpower, regulations, facilities, funding and institutions. Such capacity gaps have only propelled unscrupulous individuals and industries to pollute with impunity.

In terms of manpower, environmental conservation agencies do not have adequate staff to do the actual monitoring of polluters and the conducting of environmental impact assessments (EIAs) especially for industries. The situation has been worsened by corruption, as polluters easily part with bribes to submit poorly undertaken EIA reports. Besides, incoherent policies exist. For instance, policies encouraging food security do not really factor into consideration environmental conservation, thus while trying to increase food production, farmers inadvertently destroy the environment.

Incapacities have also been noted when it comes to facilities and institutions. Specialized equipment is required to measure and determine the extent of environmental degradation occasioned by industries. However, insufficient equipment exists since the pollution sources outnumber the available equipment. Additionally, there are not enough extension officers to train farmers on best farming practices to alleviate pollution resulting from poor land use practices. These deficiencies in the environmental management of the Lake Victoria Basin necessitate the construction, and or dedication, of institutions that can offer training for the various persons required to oversee environmental quality.

\subsection{Lack of an Integrated Lake Basin Approach}

The Lake Basin Development Authority established to undertake the overall integrated planning, coordination and implementation of programmes and projects in the basin has not been very effective in delivering its mandate. Ideally, the lake is a shared resource amongst the catchment communities, thus the challenges threatening its sustainability should also be shared amongst those communities. Cognizant of this aspect calls for a well-coordinated approach in dealing with all environmental problems, including the water hyacinth challenge in the lake. Such an approach will bring together all government authorities tasked with environmental management, water quality regulation, international donors, county governments and the national government under one umbrella, with the aim of pursuing a two-prong approach: physically eradicating the weed from the lake and mitigating the causes of the reproduction and spread of water hyacinth.

Pollution and human activities threatening Lake Victoria originate primarily from the Lake Basin counties and neighbouring counties. The war on water quality and water hyacinth eradication cannot be won by individual counties since environmentally degrading activities in the highland counties, such as poor agricultural practices and agroprocessing industries, wash sediments and pollutants into the lake, thereby encouraging water hyacinth spread and hampering fishing and water-based transportation. Addressing this inter-county problem calls for a concerted effort through an integrated Lake Basin approach.

\section{Potential Mitigation Measures to Tackle the Spread of Water Hyacinth}

As envisaged in Vision 2030, Kenya seeks to benefit from the blue economy potential of activities such as waterbased tourism and fishing in Lake Victoria. Efforts have been made by the government to combat poor water quality at the lake. For instance, in dealing with the invasive water hyacinth, mechanical, chemical and biological approaches have been employed to eliminate the weed. However, since most of the threats have been occasioned by human activities within the catchment communities, there is a need to focus on mitigation measures that address these activities from a holistic 
perspective. Such measures include: application of a polluter pays principle; agricultural extension activities; change in farmers' attitudes; political will and support; adequate financial support and addressing poverty.

\subsection{Polluter Pays Principle}

The polluter pays principle is a practice whereby those producing pollution are made to bear the costs of managing it to prevent environmental damage. The principle is primarily applied to industries that discharge harmful pollutants. However, before the principle can be applied, a survey is required to establish pollution sources and extent. Learning from China's example where a pollution census was undertaken to establish key pollution sources and pollution extent before setting reduction targets, Kenya could conduct a similar survey of polluters so that the national environmental watchdog, NEMA, can enforce the principle. The concept of polluter pays will incentivize polluters to implement measures to prevent pollution, comply with regulations and thereby avoid additional costs.

The principle has been applied in developed countries such as Canada that have the capacity to measure the extent of pollution. In Kenya however, industries discharging untreated waste water and other pollutants could be made to pay through taxes and fines when found to have contravened the set pollution limits or regulations. Additionally, NEMA could revoke licenses of factories that do not comply with pollution regulations. Proper adoption and enforcement of the polluter pays principle will result in a reduction of industrial effluents being discharged into rivers draining into Lake Victoria, thus cutting down nutrient sources for water hyacinth.

\subsection{Agricultural Extension Services}

Pollution and sedimentation emanating from agriculture has been recognized as one of the major causes of deteriorating water quality in the lake. Intensive use of pesticides and chemical fertilizers, expansion of agricultural land, and the transfer of pollutants via irrigation, have all contributed to the problem. Unsustainable land use and improper land tilling and soil management have also increased erosion and sedimentation into the lake, making it shallower and thus more conducive for the growth of water hyacinth.

To address these agricultural concerns, measures need to be undertaken to focus on best land use practices. One way of achieving this is through agricultural extension services. Public extension services were very effective up to the early 1980's before they were dismantled. Broadly referred to as advisory and other services, they entailed dissemination of user-friendly scientific research and knowledge to farmers on best practices in terms of farming techniques and inputs, with the aim of helping farmers maximize their yields and related activities. With agriculture being a devolved function, Lake Basin counties should employ extension staff to train farmers on best farming practices such as cultivation methods, rightful application of fertilizers and afforestation to prevent soil erosion.

Extension services could also help farmers adopt better conservancy activities. As noted by Obiria (2014), such services were deployed around Lake Naivasha and reduced pollution, thereby increasing sustainability as well as the survival of living organisms. In the Lake Naivasha communities, conservation agencies involved farmers in a drive to protect the lake. In that programme, farmers planted Napier grass, fruit trees and cock's-foot grass on their slopping farms, which reduced the amount of soil washing into rivers. Additionally, universities within the Lake Basin counties could be involved in the provision of extension services through the training of staff and farmers.

\subsection{Change of Farmers' Attitudes}

From the foregoing discussion, pollution of Lake Victoria and the subsequent spread of water hyacinth is largely attributable to human activities of the catchment communities. It is worth noting that the majority of communities, especially most farmers, are not aware of the effects of their land use practices on the lake and consequently they continue to pollute it. To change this scenario, there needs to be a change in the attitudes of farmers with regards to how they interact with their land. One such approach towards changing attitudes would be through information dissemination on the impacts of improper land use activities on water pollution and sedimentation, and the resulting proliferation of water hyacinth.

Lake Basin communities should be encouraged to embrace new innovations and quit traditional farming practices. Learning from the example of Indonesia, where soil conservation measures such as greening and terracing have been employed and have reduced soil losses by up to $70 \%$, could be instructive for the local farmers. Further, Zadeh et al. (2017), recommended that cooperative and voluntary agreements between farmers and water authorities can install better environmental practices in agriculture.

Finally, identifying and pursuing alternative sources of livelihoods, that are more environmentally resilient, should be encouraged to ease the pressure on natural resources.

\subsection{Political Will and Support}

For many years the lake basin region has been a political opposition stronghold and has been marginalized especially with regards to government programmes, a practice common in developing countries. However, over the recent past this has changed with the collaboration between President Uhuru Kenyatta and his counterpart, former Prime Minister Raila Odinga. The duo has visited Kisumu port several times with a bid to fast-track ongoing rehabilitation work that is expected to come to completion in August 2019. This comes in the wake of focussing on the blue economy. The Kenyan government has invested Kshs 3 billion for work that will see a facelift to the port, dredging of a harbour and the clearing of water hyacinth. Such political support should steer the water hyacinth eradication project to fruition.

Communities are greatly influenced by politicians. If politicians take the lead role in supporting programmes that address environmental challenges, catchment communities are likely to follow. Recognizing that Lake Victoria is important to the 
blue economy, the government must fully support efforts geared towards improving the lake's sustainability. This can be achieved through legislation and endorsement of projects that seek to conserve the waters and adjacent land around the lake. Additionally, the government could solicit support from major donors and partners to help not only in actual removal of the weed, but also with regards to supporting the modification or eradication of activities that currently support the proliferation of the water hyacinth.

\subsection{Adequate Financial Support}

Over the last two decades, attempts have been made by the World Bank and other donors, through the LVEMP, to improve the management of Lake Victoria. The LVEMP has been rolled out in two phases, but the results have been mixed. Through this programme, understanding of the challenges faced by the lake has improved and pilot projects geared towards reducing pollution, watershed rehabilitation and water hyacinth reduction, have also been implemented. However, funding for the program has not been sustained, in part because of the phased nature of the funding model. The nature of the water quality, and associated water hyacinth, problem, necessitates sustained and long-term financing if the weed is to be completely eradicated. Such a programme will only succeed with multiple sources of funding from all three Lake Victoria national governments, international donors and partners.

Related programmes such as those promoting good urban governance should be financed as they have a direct influence on urban management, which in turn could reduce pollution originating in urban areas. Additional finances are required to train agricultural extension staff and staff in water regulatory bodies to build their capacity to deliver quality services. This will enhance timely and effective monitoring and enforcement of water quality regulations and hence curb excessive industrial and agricultural pollution.

\section{Conclusion}

If there is to be any prospect of eradicating - or at least controlling - water hyacinth on the Kenyan side of Lake Victoria, there is an urgent need for the Lake Basin counties to implement an effective integrated basin management approach which addresses both the causes of water hyacinth spread and the actual removal of the weed. This could be achieved by tackling catchment activities that cause sedimentation and pollution such as environmentally unsound landuse practices, uncontrolled urbanization, and large-scale poverty. Programmes to build capacity in the area of agricultural extension will be very effective in overcoming the widespread ignorance among farmers of environmentally damaging practices and changing their attitudes - and possible reluctance - to the adoption of more sustainable farming methods. Environmental regulations simply must be more effectively implemented and enforced, including the polluter pays principle, to put an end once and for all to the current situation where industries are polluting with impunity. In addition, coherent policies are needed which are aimed at increasing agricultural and industrial production, while at the same time mitigating water pollution.

All these interventions require adequate financing and political support at the levels of the individual Lake Basin counties and the different subregions and also at national level. Lake Victoria is an asset of immense value not just to Kenya, but to the entire world, and more than one fourth of the country's population is directly dependent on it for their livelihood. At the 2018 Sustainable Blue Economy Conference, the Kenyan Government committed itself to attainment of a number of its own sustainable development goals, one of which was "to increase funding to address the water hyacinth problem at Lake Victoria." Furthermore, for Kenya to achieve its Vision 2030, a concerted effort is required by all stakeholders within the Lake's catchment area, not only to change their current environmentally damaging practices, but also to ensure that future activities do not exacerbate the sedimentation and aquatic pollution that enables the invasive water hyacinth to thrive

\section{Acknowledgements}

I would like to thank Mr. Nobert Maina, AFICS-K intern, for his contributions. The views and opinions expressed in this article are those of the author and not of AFICS-K.

\section{References}

i. Cock, M. (2001). Problems Caused by Water Hyacinth as an Invasive Alien Species. Wallingford.

ii. Deloitte. (2015). The Lake Region Economic Blue Print: A better life.

iii. Ellsmoor, J. (2019, January 26). Rethinking our Oceans: Investing in the Blue Economy. Retrieved from Forbes website: www forbes.com

iv. Makhanu, K. S. (1997). Impact of Water Hyacinth on Lake Victoria. Water and Sanitation for all: Partnerships and Innovations, (pp. 165-166). Durban.

v. Muyodi, J. F., Semili, P., Maturwe, N. B., Okungu, O. J., Semalulu, O., Wanda, F., Hecky, R. E. (2011). Water, Communities and Development in the Lake Victoria. In Lake Victoria Environment Report (pp. 141-172).

vi. Nyabundi, D. (2019, March 01). Kisumu firms raided over Lake Victoria pollution. Retrieved from Standard Digital: www.standardmedia.co.ke

vii. Obiria, M. (2014, June 3). Better Farming practices cut pollution of Lake Naivasha. Business Daily.

viii. PAI. (2015). Population Dynamics, Environment and Sustainable Development in Homa Bay County.

ix. SBEC. (2018). Report on the Global Sustainable Blue Econonomy Conference 26th- 28th November 2018. Nairobi, Kenya. Nairobi.

x. Sims, J. (2019, April 11). BLUACT: Why the Blue Economy is an increasing sea of opportunity. Retrieved from https:/ / urbact.eu/ bluact-why-blue-economy-increasing-sea-opportunity 
xi. UNDP. (2018, April). Leveraging the Blue Economy for Inclusive and Sustainable Growth. Policy Brief (6).

xii. UNESCO. (2016). A Systematic Review of Effects of Emerging pollutants on Human Health and Livelihoods of Population living in the Lake Victoria Basin of Kenya.

xiii. World Bank. (2018). Lake Victoria Environment Management Project III. World Bank.

xiv. World Bank. (1996). Lake Victoria Environment Management Project. World Bank.

xv. Zadeh, s. M., Turral, H., \& Sagata, J. (2017). Water pollution from agriculture: a global review. Rome: Food and Agriculture Organization of the United Nations. 